\title{
Correspondence
}

\section{Failure to show a fall in peripheral blood lymphocytes in patients receiving gold or penicillamine for rheumatoid arthritis}

SIR, We read with interest the paper by Hanly and Bresnihan on the reduction of peripheral blood lymphocytes (PBLs) in patients receiving gold therapy for rheumatoid arthritis (RA). ' We report our own study in which we sought to verify this finding in a larger patient population.

The data of 111 patients with definite or classical RA who were receiving gold (58 patients) or D-penicillamine (53 patients) were reviewed. The two groups were comparable for age, sex ratio, and disease duration, though there were more seropositive patients in the D-penicillamine group. All patients had received therapy for at least 12 months, and it had been considered successful in controlling or reducing disease activity by both clinical and laboratory criteria (Table 1). The absolute PBL counts for each patient were available at () (pretreatment), 1, 3, 6 . and 12 months. Statistical analysis was performed using parametric tests; this was possible as after subtraction of the initial (pretreatment) value from each of the remaining counts for every patient the differences fell into a normal distribution.

Regressions on individual profiles, regression analysis on the overall data set, and analysis of variance were obtained on both therapy groups, separately and in
Table 1 Characteristics of the two patient groups

\begin{tabular}{|c|c|c|}
\hline & $\begin{array}{l}\text { Gold } \\
(n=58)\end{array}$ & $\begin{array}{l}\text { D-Penicillamine } \\
(n=5.3)\end{array}$ \\
\hline Male:female ratio & $201: 38$ & $24: 29$ \\
\hline Mean age, range (years) & $53 \cdot 2.24-73$ & $57 \cdot 1.19-80$ \\
\hline $\begin{array}{l}\text { Mean discase duration. } \\
\text { range (years) }\end{array}$ & $4 \cdot 3,0 \cdot 5-23$ & $7 \cdot(1) \cdot(0 \cdot 5-2.3$ \\
\hline Seropositive & 23 & 38 \\
\hline \multicolumn{3}{|l|}{$\begin{array}{l}\text { Erythrocyte sedimentation } \\
\text { rate }(\mathrm{mm} / \mathrm{h})\end{array}$} \\
\hline At the start & $48(27)^{*}$ & $+3(28)$ \\
\hline After 12 months & $32(21)$ & $25(17)$ \\
\hline \multicolumn{3}{|l|}{ Hacmoglobin $(g / l)$} \\
\hline At the start & $120(1.3 \cdot 7)$ & $120(17)$ \\
\hline After 12 months & $12+(21 \cdot 3)$ & $128(12 \cdot 8)$ \\
\hline \multicolumn{3}{|l|}{$\begin{array}{l}\text { Absolute Iymphocyte count } \\
\quad \times 10^{-11 / 1}\end{array}$} \\
\hline At the start & $2.16(0.7 .3)$ & $1.86 \quad(0 \cdot 6)$ \\
\hline After 12 months & $2 \cdot 1(0 \cdot 6)$ & $1.4(0.56)$ \\
\hline
\end{tabular}

"Values are mean (SD).

combination. There was no significant difference in the values obtained in the two groups at any time. Fig. 1 shows the number of patients in whom it was possible to obtain a regression line (18 gold treated patients and $15 \mathrm{D}$ penicillamine treated patients) and demonstrates that a fall in the absolute PBLs is no more likely to occur than a rise in either group $(p>0 \cdot 1)$. Regression analysis of the two groups as a whole came to the same conclusion $(p>0) \cdot 5)$.

From this data we were unable to confirm the findings of the previous study: no change in the absolute lymphocyto count occurred during the initial 12 month period of
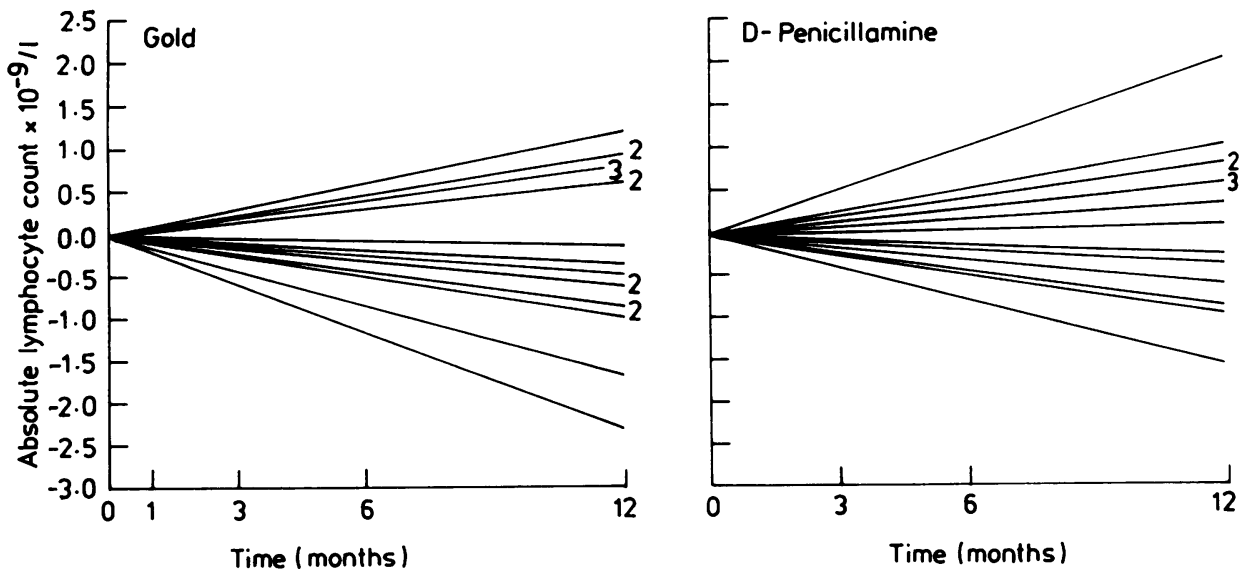

Fig. 1 Significant individual regressions (differenced data). 
effective therapy with either gold or D-penicillamine. This does not, however, exclude the possibility that change in selective lymphocyte populations or in lymphocyte function may be occurring.

City Hospital, Nottingham

M ISHIGAMI A J CHUCK A J SWANNELL M DOHERTY

University Department of Mathematics, K GORDON Nottingham

\footnotetext{
Reference

1 Hanly J G, Bresnihan B. Reduction of peripheral blood lymphocytes in patients receiving gold therapy for rheumatoid arthritis. Ann Rheum Dis 1985; 44: 299-301.
}

SIR, There are important differences between the study of Ishigami et al and our report ${ }^{1}$ which may explain the apparently discordant findings. Ishigami's study included 58 patients treated with gold over a 12 month period. Although we are not told, one assumes that the gold preparation and the dose schedule used were similar in both studies. In Ishigami's study gold therapy was 'considered successful in controlling or reducing disease activity by both clinical and laboratory criteria'. The only data offered in support of this claim, however, are changes in erythrocyte sedimentation rate (ESR) (Westergren?) and peripheral blood haemoglobin levels. If the pretherapy ESR values in the two studies are compared (mean (SD): 48 (27) Ishigami et al; 59 (25) Hanly and Bresnihan) it would appear that the latter group of patients had more active disease. Furthermore, the six month post-therapy ESR in our study (mean (SD): 24 (11)) compared with the 12 month post-therapy value in the study of Ishigami et al (mean (SD): 32 (21)) indicates a greater reduction in disease activity in the former group. This may be important as, in our study, the greatest fall in peripheral blood lymphocytes occurred with the initial and most marked reduction in disease activity. Therefore, such a change may not be apparent in patients whose pretherapy disease activity is less marked and who have a less dramatic reduction in disease activity with gold therapy.

As Ishigami's study is a retrospective review, presumably detailed assessments of articular disease activity were not available on all patients. Such data are essential to allow accurate measurement of the response to therapy. Some patients clearly had a fall in lymphocyte counts while receiving gold therapy and one wonders if these patients also had the greatest reduction in disease activity.

We have seen our initial findings reproduced in additional patients currently entered in a prospective study of gold therapy in rheumatoid arthritis (unpublished observations, Rooney and Bresnihan). Total circulating lymphocyte counts, however, may be too insensitive to detect changes in all such patients. As Ishigami et al point out the absence of a fall in the total lymphocyte count does not preclude changes in lymphocyte subpopulations and lymphocyte function, as recently reported by Hassan et al. ${ }^{2}$

Department of Rheumatology,

JOHN HANLY St Vincent's Hospital,

BARRY BRESNIHAN

Elm Park,

Dublin 4, Ireland

\section{References}

1 Hanly J G, Bresnihan B. Reduction of peripheral blood lymphocytes in patients receiving gold therapy for rheumatoid arthritis. Ann Rheum Dis 1985; 44: 299-301.

2 Hassan J, Hanly J G, Bresnihan B, Feighery C, Whelan C A. The immunological consequences of gold therapy: a prospective study in patients with rheumatoid arthritis. Clin Exp Immunol 1986; 63: 614-20.

\section{Serum lactic dehydrogenase as a marker of joint damage in rheumatoid arthritis}

SIR, The finding that raised serum lactic dehydrogenase (LDH) levels were linked with progressive joint damage in patients with rheumatoid arthritis (RA) reported by Dawes and colleagues underlines the potential usefulness of biochemical markers of tissue turnover. ${ }^{1}$

Vessel et al reported that synovial fluid from patients with RA showed the polymorph LDH isoenzyme pattern. ${ }^{2}$ We have found raised ( $>2$ SD) serum LDH in $22 \%$ of 32 outpatients with RA, and in 12 paired samples the mean (SD) ratio of synovial fluid:serum LDH was $4 \cdot 3(3 \cdot 4)$. There was close correlation between synovial fluid leucocyte count and LDH level $(r=0.93)$.

These data support the synovial fluid polymorph as the source of raised serum LDH and suggest that, like cytidine deaminase,${ }^{3} \mathrm{LDH}$ is released from dead and damaged cells into the synovial fluid and diffuses, via the lymphatics, from all inflamed joints to the blood. Serum levels reflect overall polymorph turnover as a measure of joint inflammation.

The finding that such a measure might predict the progression of joint damage offers hope to the clinician and may shed new light on the relation between aspects of inflammation and joint destruction.

Cytidine deaminase, with higher cell:serum gradient and lower serum background than $\mathrm{LDH}^{3}$ may offer even greater sensitivity.

Bone and Joint Research Unit, PAUL W THOMPSON The London Hospital Medical College,

Turner Street,

London E1 2AD

Department of Biochemistry, DILWYN D JONES

Bronglais Hospital,

Aberstwyth,

Dyfed

\section{References}

1 Dawes P T, Fowler P D, Jackson R, et al. Prediction of progressive joint damage in patients with rheumatoid arthritis receiving gold or D-penicillamine therapy. Ann Rheum Dis 1986; 45: 945-9.

2 Vessel E S, Osterland K C, Bearn A G, Kunkel H G. Isoenzymes of lactic dehydrogenase; their alterations in arthritic synovial fluid and sera. J Clin Invest 1962: 41: 2012-9.

3 Thompson P W. Jones D D. Currey H L F. Cytidine deaminase activity as a measure of acute joint inflammation in rheumatoid arthritis. Ann Rheum Dis 1986; 45: 9-14. 